\title{
Research on the integration of production, processing and sales in marketing of China's agricultural products and the improvement of market performance — Taking the rice industry in Heilongjiang province as an example
}

\author{
Dezhang WANG' ${ }^{1}$, Jiali $\mathbf{L I}^{2}$ \\ 1Harbin University of Commerce \\ 2Heilongjiang Institute of Technology
}

\begin{abstract}
Problems from PPS (production, processing and sales) of China's agricultural products has attracted many attentions of the society, related to the interests of farmers, agriculture organization, enterprises and consumers of urban and rural. Over many years, the unstable supply of agricultural products and the fluctuations in price have affected the increase of farmers' income and the interests of consumers. In the case, government should subsidies to farmers or aid to low-income groups in rural and urban in order to reduce the effects, although the adjustment is in a passive situation. It should be noted that what causes the unstable supply and the fluctuations, the paper points out that the reason of the contradiction between small-scale production and big market, and this can be improved by integrating resources, making the industrial group of IPPS (Integration of Production, Processing and Sales) more bigger, innovating the ideas of macro-control and changing the concept of marketing.
\end{abstract}

Key words: IPPS, agricultural products, innovating macro-control

1. The marketing mode of IPPS is the requirement of management innovation under the new situation

1.1. Changing the marketing concept is fundamental in IPPS

In a long period, the marketing concept of enterprise is based on profit as the main target; they often pay attention to their own interests and ignore the interests of relevant subjects. To some extent, they realize their own benefit at the expense of the interests of the related subjects, this short-term marketing behavior does not accord with the social marketing concept, but also not conducive to the long-term stability and sustainable development of enterprises. Under the new situation, enterprises need to meet the requirements and take improving social welfare, obtaining reasonable profit (benefits to farmers and consumers) as the marketing concept. This requires innovating the marketing mode to cooperative competition, strengthening cooperation with agricultural organization and enterprises from upstream and downstream in the industry chain. The enterprise of IPPS (Integration of Production, Processing and Sales) should achieve the long-term stable growth of profit through economies of scale, brand and customer loyalty, that is to say, when the enterprise improve business performance, some related interest subjects can get profit.

1.2. Optimizing the structure and coordinating the interest relationship is the key in IPPS

At present, the marketing mode of agricultural products can be divided into two kinds in China, one is SPPS (Separation of Production, Processing and Sales), and another is IPPS (Integration of Production, Processing and Sales) (close and loose). According to the investigation and prediction from the rice industry of Heilongjiang province, the proportion of IPPS and SPPS each will reach to $50 \%$ by the end of 2012. IPPS and SPPS have different influence on the increase of farmers' income, enterprises' benefits and the development of regional economy. Therefore, increasing the proportion of integrated marketing model and optimizing the structure will play the positive role in improving the comprehensive performance better. In IPPS, the proportion of close IPPS or loose IPPS should reach to $50 \%$ that IPPS is helpful to improve the market competition. In the advancement of IPPS marketing, the key is to coordinate the relationship between the interest subjects, especially the relationship between farmers and enterprises, agricultural organizations and enterprises, enterprise and market, enterprises and consumers, so that they can be properly placed and make competition orderly. 


\subsection{The affecting action of leading enterprises is the core in IPPS}

In a successful marketing of IPPS, there is a large leading enterprise that affects the base, farmers, cooperatives, and it has close links to the community supermarkets, wholesale markets and community characteristics. This is the main way to solve the contradictions between smallscale production and big market, at the same time; this is also a solution to reduce the circulation and an effective way to reduce logistics costs. China's agricultural market has relationship with the amount of leading enterprises which have famous brands more or less. Therefore, promoting the development of large enterprises is the core that affects the increasing of farmers' income, enterprise efficiency, the development of local economic and consumers' benefit. From a development point of view, the mode of mainly processing enterprises have maintained a good momentum of development because of the geographical advantages at present stage; From the development strategy, the mode giving priority to business enterprise has more development potential, because the channel advantage is more and more important in the competition of market; In the developing, cooperation between processing and business enterprise will become the focus of the integration of resources, in this way, the cooperation between enterprises will bring more farmers, agriculture organization developing better.

1.4. Doing a good job in macro-control and supervision is the guarantee in IPPS

Market regulation and oversight has an important role. One is embodied in the regulation and oversight of production, the link of processing mainly is to increase supply and guarantee the quality and safety, protect the farmers income stable growth in the interest adjustment, but also manifests the policy guidance of the great leading enterprises supported; The other is embodied in the link of sales, it mainly is the quality and safety of guarantee which prevents monopoly, reduces circulation, reduces logistics cost, stables prices and protects consumers' rights and interests; Three is creating a good marketing environment through innovating management, enhancing the level of regulation and oversight and strengthening service.

The role of market and government should be clearly defined. First, market regulation and government role of positioning should be clear in the agricultural products, especially in major agricultural products market which influences the development of national economy and people's livelihood; In a long period, there is a myth on the level of management and operation, it is to let the market play a more role of regulation in market economy neglecting and weakening the regulation of the market, especially the role of increasing farmers' income and protecting urban and rural consumers' rights and interests. Production, circulation and consumption of agricultural products is related to the farmers' income and project of people's livelihood, in a long period of time, we should to play the role of the two aspects of market regulation and government regulation, and we should to strengthen and improve the government control in particular; Second, it is to clarify questions about competition and monopoly, the competitive market environment should be gradually formed that is advantageous to competitive, and it has a positive role in increasing the supply of agricultural product, also in improving security and quality of agricultural products. In the current situation, farmers and agriculture organization is the processing enterprises, and business negotiation deals more vulnerable; this kind of situation easily happened strong side exploit weak side. In recent years, the monopoly in market of agricultural product has formed during the process of competition, also formed man-made. In the case of market demand remaining the same, big business and big dealer affect the price of market under the profit-driven by controlling the supply of commodity in a certain period of time to obtain huge profits; it is precisely the behavior of monopoly market, amplifying the fluctuation of supply and demand and price. Therefore, the departments of market management should attach great importance to the market monopoly phenomenon by preventing and combating monopolies.

\section{The positive role of marketing mode in IPPS}

Wuchang is a famous area for rice which is a city of Heilongjiang province in our country, its natural environment is good, and it has a long history of cultivation while the technology of production and processing is advanced and renowned at home and abroad market. The rice of Wuchang City has three regional advantages brand, "China geographic indication products", "Geographical indications of agricultural products certification marks" and "Chinese famous brand products".

\subsection{The characteristics of marketing model in IPPS and SPPS}

Agricultural IPPS reflects a country or a region of industry and the development level of the enterprise, combined IPPS good promote farmers' income and efficiency of enterprises and local economic development; It is a business form reform of farmland circulation, family and the effect of the policy guidance. On the other hand, for the market management, protection of the rights and interests of consumers and to track the traceability are more difficult.

Marketing model and characteristics of SPPS. SPPS refers to farmers, agriculture organization responsible for the production; processing enterprises are responsible for processing and sales business or market a marketing mode, responsible for selling the IPPS performed by different economic organizations or individuals. It is small and medium-sized rice processing enterprises, relying on 
geographical advantages and simple processing equipment, the farmers to buy rice processing after the sale. Due to small size and simple processing equipment, product positioning is the low-end market, and due to a lack of mastery of market supply and demand information and sales weak wait for a reason, is the origin of wholesale markets, sales channels mainly used the bazaar or sold through brokers to group buyers. There are leaks in this case, if the market management is more vulnerable to counterfeit market phenomenon.

Marketing model and characteristics of IPPS. IPPS points to establish a contract to buy rice or renting land by processing rice or a commercial enterprise mainly with the agriculture organization, standardization of large-scale rice production, and form marketing model of IPPS after processing to the market. Its main characteristic is in processing or commercial enterprises under the affect of the organic combination of production, processing and sales link, its purpose is to improve IPPS organizational degree to achieve economies of scale, standardized operation, and improve the comprehensive market performance and from field to table a package of quality engineering.

IPPS is divided into two cases. Rice is a kind of "Sunflower sunshine co., LTD. (in 2005), the amount of grain abundant organic cereal products co., LTD. (in 2007), as a representative of leading processing enterprises. This is a kind of market-oriented, to rent a large number of farmers land and construction of production base, with farmers, farmers scot conclude a contract for the purchase or lease part of farmers land, continuous base for large-scale development, guarantee the seed, fertilizer, technology can satisfy the requirements of the production of high quality rice. After deep processing of rice through stores, large supermarkets, wholesale markets such as channel sales. Common characteristic of this kind of mode is: enterprises with existing brand, market impact, channel advantages and strength, in different ways and rice association (cooperative) and the farmers, grasp quality rice resources, rely on advanced processing equipment for processing, mainly through the size of the supermarkets, chain stores and specialty stores to sell its products, mainly for medium and high-end market and corresponding consumer groups, namely rice "market + company + association (cooperative) + farm households (base) + supermarket + stores" marketing model.

Another is a delegate with large business enterprise of the central red group circulation enterprises (2006) and local enterprise cooperation and win-win development pattern, namely "market + enterprise alliance (cooperative) + farmers + association (base) + + size supermarket stores". This kind of mode has the following main features: first, the circulation of urban commercial enterprises business extends to the countryside, directly in joint venture way, USES the advanced processing equipment, to participate in product processing, through cooperation with the local processing enterprises realize the complementary advantages. The central red group have a successful business model and their own sales channels and its own brand advantage, throughout the urban and rural chain stores, supermarkets and Harbin, Beijing is better and faster development; The second is win-win cooperation develops the market. The central red group using the central shopping malls supermarkets and small moon chains, and set up shop in Beijing to develop high-end rice market, the enterprise economic benefits increase as well as the amount of rice industry promotes the development and farmers' income. The above two modes and three forms can be illustrated by figure 1 .

Enterprises 1 on behalf of the small and medium-sized processing enterprises, processing of rice mainly comes from to the farmers, agriculture organization scattered acquisition, processing and product the corresponding sales channels mainly wholesale market, market and bulk, the corresponding is the low-end market and the lowincome groups;

Enterprise 2 is a delegate with sunflower sunshine which is a large-scale processing enterprises, they take the market as the guidance, through acquisition, order, lease, and association and farmers to establish a relatively stable relationship of interests, based on a through deep processing and brand advantage, using size supermarkets and stores to develop medium and high-end market in big cities, the corresponding is the consumer groups, high income, this model is helpful to increase farmers' income. Enterprise 3 is a delegate with the central red group enterprise alliance, which is based on the existing channel, brand, and the basis of the successful business model, thus forming the integration of sales, processing, and production of co-petition marketing model. To be in sales channel types corresponding consumer groups, divided into often purchase behavior as the basis, we do not rule out a small amount of purchase, accidental across channels. Through the above two modes and three types of analysis, the conclusion is: the first type of enterprises will gradually reduce, the second and the third type of enterprises will be increased, and this also is the development requirements of the restructuring.

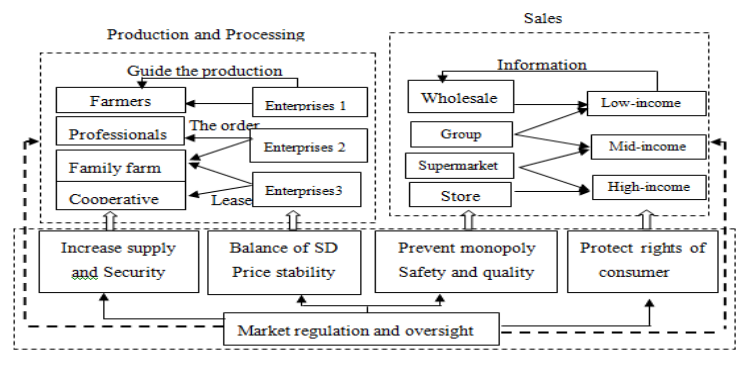

Figure 1 Marketing model of IPPS and the constituent elements of agricultural products 
2.2. The role of marketing mold in IPPS for farmers to increase income, for enterprises to improve the efficiency and for local government to promote economy.

To compare the performance of the market mode in SPPS and IPPS, we put the amount of rice industry development is divided into three stages, 2004-2006 is the stage of SPPS while 2007-2009 is the primary stage of IPPS and 2010-2012 is the intermediate stage of IPPS.

The impact on the farmers' income. Can be seen from table 1, in 2004-2006, per capita net income of farmers grew at an annual rate of $8.16 \%$ per year; In 2007-2009, farmers per capita net income of the average annual growth rate of 15.65\%; Annual in 2010-2012, farmers' income is $21.99 \%$, through the analysis of large data, shows that the integration compared with the separation of marketing model can drive the farmers' income, especially in the intermediate stage is more obvious.

The influence on enterprise efficiency. Impact on enterprise efficiency can be through the following two aspects, on the one hand is the comparison of the cultivated area and yield, on the other hand is the comparison of yield and output value. Can be seen from table 1 , one is in the three stages of production are higher than the growth of cultivated land increase, the second is the output value is higher than the growth of output growth, this suggests that under the condition of other condition is constant improve the enterprise benefit. To be sure, in the intermediate stages of integration is given priority to, the development strategy of the enterprise from scale expansion to rely on the brand and the development of science and technology, it reflects the stability of ascension and laid the foundation for later development.

The impact on local economic development. See from table 1 , in three stages, the relationship between rice production and GDP, all showed a positive correlation, in recent years, the rice output contribution to GDP is in the rise, and indicates that the development of rice industry vigorously promoted the development of local economy.

\begin{tabular}{c|c|c|c|c|c|c}
\hline Year & Land & $\begin{array}{c}\text { Planting area } \\
\text { of rice }\end{array}$ & $\begin{array}{c}\text { Yeld of } \\
\text { rice }\end{array}$ & $\begin{array}{c}\text { Output of } \\
\text { rice }\end{array}$ & $\begin{array}{c}\text { Net income of } \\
\text { farmers }\end{array}$ & GDP \\
\hline 2004 & 372.89 & 145.00 & 82.19 & 17.5 & 3899.00 & 86.5 \\
\hline 2005 & 372.89 & 160.00 & 90.00 & 20.3 & 4340.30 & 89.7 \\
\hline 2006 & 372.89 & 165.00 & 95.00 & 21.3 & 4561.00 & 100.5 \\
\hline 04.06 av $(\%)$ & 0.00 & 6.67 & 7.51 & 10.32 & 8.16 & 7.78 \\
\hline 2007 & 387.54 & 175.50 & 100.00 & 26.0 & 5385.00 & 118.6 \\
\hline 2008 & 387.95 & 175.70 & 117.00 & 35.9 & 6098.00 & 138.4 \\
\hline 2009 & 387.95 & 178.90 & 123.00 & 50.0 & 7202.00 & 162.7 \\
\hline 07.09 av (\%) & 0.05 & 0.96 & 10.91 & 38.68 & 15.65 & 17.13 \\
\hline 2010 & 388.75 & 180.78 & 136.40 & 69.34 & 8496.00 & 195.2 \\
\hline 2011 & 399.76 & 188.00 & 139.00 & 89.85 & 10195.00 & 232.2 \\
\hline 2012 & 408.50 & 200.70 & 155.79 & 114.45 & 12234.00 & 275.0 \\
\hline $10-12$ av $(\%)$ & 2.50 & 5.50 & 7.10 & 32.53 & 21.99 & 18.69 \\
\hline
\end{tabular}

Table 1 The main economic indicators of PPS in rice of Wuchang City at different stages

The impact on consumers. Harbin city as PPS combined with pilot cities across the country, by the year 2015 are planning to open 30 produce standardized market in April 2014 , opened a shop around the fruit price is $10 \%$ lower than the general market, the main reason is that IPPS for its scale, reduce cost, reduce the link laid a foundation; In addition, the government's policy guidance also played a role.

\section{Problems need to be solved to promote the marketing model of IPPS}

3.1. Promote the structural optimization through policy innovation

Agricultural products marketing model structure optimization is the concrete embodiment of transfer mode, adjust structure, mainly includes: one is to improve the proportion of marketing model of IPPS, the second is to promote the integration of leading enterprises by resources, expand the scale of land management and standardization level of production and processing, a new round of the reform of farmland circulation and family mode of operation provides better opportunities for its, three is the reform of the rural family business forms and speed up the land circulation, also requires IPPS to speed up the process, the fourth is to improve the level of peasant household production organization, the positive development of the family farm, professional investors and professional cooperatives, etc., and improve the ability of negotiation with the relevant enterprises; Five is to encourage producers into IPPS development pattern actively, on the one hand can reduce market risk, on the other hand, in the form of labor compensation industry share of the profits.

\subsection{To promote further supervision and regulation of the market}

Production and processing link is the foundation. It is the guarantee quality safety and increase supply, it is regulating the price stability and prevent monopoly; one of the three is to promote the farmers' income as the main target. From 2013 to 2020 is the farmers' income has great difficulty, so should promote the farmers' income as one of the main goals of agricultural products circulation system construction increasing farmers' income. First, through improving agricultural cooperation organization of organization scale, second, more stable by establishing and improving special agricultural subsidies, increase direct subsidies to grain producers, subsidies for growing superior seed varieties, such as agricultural machinery purchase subsidy policy, continuously expand the scope of agricultural subsidies, prompted farmers metastatic income increasing, the third, through promoting urbanization, reducing the agricultural population, let share more agricultural achievements, the less the fourth, to improve farmers' quality, improve the agricultural science and technology innovation to realize the peasants' income. 
The key link is a further play good circulation of supply and demand and price of the guiding function of information, to guide farmers and enterprises PPS; it is further defined sales channel selection positioning and consumer groups, accordingly to farmers and the production and processing of the enterprise to provide the specific service requirements, reduce the information distortion of farmers and enterprises investment risk of misleading; Three is to drop all sorts of "institutional cost", to ban all kinds of unreasonable fees. The influence of the logistics links, for example, lower logistics costs into the terminal sale price should be given priority to "thin", not just rely on a "limit order", through the open system, such as "green channel" really care consumers benefit from the source; Four is to innovate industrial chain, the relationship between the subjects to the further development of the mode IPPS, in order to improve the trade efficiency, reduce transaction costs and reduce the intermediate links markup percentage; Five is to reduce market access standard, break between different areas in both production and marketing and local protectionism, ensuring the market of agricultural products in the highly competitive; Six is to speed up the traceability system construction to ensure the safety of food.

\subsection{Let the leading enterprises more stronger and bigger by integrating resources}

The three kinds of enterprises to seize market opportunities for development. It is for small and medium-sized processing enterprises, should speed up the cooperation with large enterprises, to make it more share interests of IPPS, and avoid market risks for small enterprises; The second is for processing enterprises, due to the geographical advantages can be more mergers and acquisitions of small and medium-sized enterprises, its scale expansion, make better use of the idle processing capacity; Three is for urban commercial enterprises, should be a variety of ways of cooperation with production, processing department, on the one hand, collaborative approach to expand the scale of the enterprise itself, on the other hand, can also with the aid of business enterprise production and processing industry of channel advantage, change marketing lag situation.

The government through policy guidance to speed up cultivating leading enterprises. Encourage support large rice group consolidation mergers system of rice, small and medium enterprises in joint cooperation way, make leading enterprises play a gathering effect, forming around the leading enterprise of professional production base and regional distribution form. Should do the following three points to introduce and cultivate leading enterprises, implement the strategy of large group: one is to by encouraging private capital investment, enterprise merger and reorganization, increasing financial support, to realize the change of agricultural enterprises from small to large, efforts to introduce and cultivate a batch of large scale, science and technology with the highest, drive the ability of leading enterprises, agriculture enterprises in the number and quality of the breakthrough, and to expand the scale of the drive and improve the ultimate goal of increasing farmers' income. The second is to support the development of large enterprises and brand products. Support leading enterprises in construction of high standard varieties of rice research and development centers, research and develops the seeds, intelligent rice seedlings, fully mechanized, science and technology and social service, fine processing of rice, scale, quality, standard, and benefit the synchronous ascension. It encourages enterprises to apply green food rice cultivation mode with the digital and information-based management. Big companies and groups use Wuchang rice resource advantage to build China's first brand of high-end rice with big enterprise well-knowingness, economic strength, and the implementation of brand strategy. It is listed on the financial; the government should strengthen the capital operation, futures, guarantee policy support. Solve the problem of VAT high agricultural product processing industry low buckle, reduce the corporate tax burden; Solve the agricultural enterprise listed financing channels, development of new type joint guarantee, order the pledge loan guarantee way for expanding the scope of the rural collateral effectively, alleviate agricultural products processing enterprise financing difficult problem.

\subsection{To strengthen the protection of rural and urban low-income groups}

From consumer groups with the corresponding retail channel relationship, health security, the pursuit of lowincome groups, main channel should be given priority to with off-price stores to buy; High earners pursuit of safety, health and nutrition, the corresponding purchase channels is more, can be seen in figure 2. Off-price stores (such as Daqing in Heilongjiang province, Mudanjiang, fruit offprice stores) was presented for rural and urban lowincome groups, is the high market prices through the offprice stores provide parity to low-income groups, this part makes the interests of consumers from harm; Temporarily haven't conditions to establish off-price stores where when the market price is higher, to a certain subsidies for low-income groups, is used to compensate the price is too high for the damage. Parity of agricultural products in retail stores (stores) sales price is $20 \%$ lower than the market average price of vegetables and other agricultural products is low $10 \%$, sales of the type, quantity, quality, price level, and so on all can get effective guarantee, and adjusted according to different season. Government can according to the principle of "control before fill" replace subsidies with awards, in the form of offer certain economic rewards. 


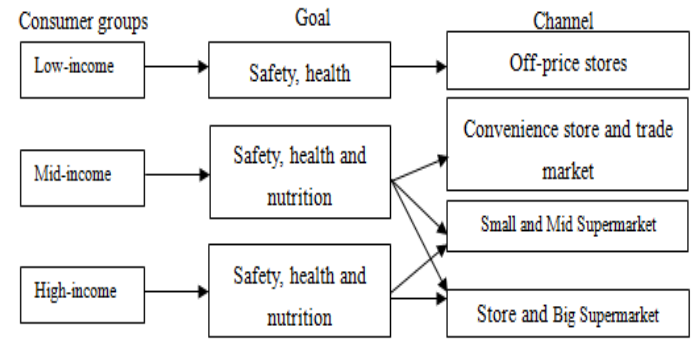

Figure 2 is suitable for different consumer groups of major retail channels

\subsection{To strengthen the construction of market regulations and related mechanism}

In marketing model of IPPS, the process of the construction and integration of agricultural products will speed up the construction of the rule of law. One is to establish and perfect food safety regulations, improving of major agricultural products circulation system from the legal regulation. Second is to establish and perfect relevant laws and regulations govern the major agricultural products monopoly. Three is to establish and perfect the emergency response mechanism of agricultural product prices. Special reserve system, including important protective price of agricultural products and agricultural products price regulation fund system, set up agricultural social service system, to ensure the healthy and orderly operation of major agricultural products market. Four is for food safety to strengthen the regulation of grassroots coverage, intensify quality disciplinary, change to hosting situation to ensure the supervision of the consumers, this is to protect the rights of consumers of goods and services to supervise, and to supervise consumer rights protection work, especially when the lawful rights and interests are violated, where you can have a complaint and get the rights and interests protection solutions. Five is to increase supervision of agricultural capital market, maintain the agricultural materials prices basically stable, ensure the supply of agricultural capital market prevent prices for agricultural supplies from rising too quickly, reduce the farmer household production cost spending, reduce the agricultural production and operation costs, make the farmers enjoy the preferential policies at the same time, get a substantial increase.

\section{Conclusions and Perspective}

Through the analysis, this paper draws the following conclusion: In order to promote the marketing model of IPPS, the government should promote the structural optimization through policy innovation and promote further supervision and regulation of the market. At the same time, it is necessary to let the leading enterprises more stronger and bigger by integrating resources. More important, the protection of rural and urban low-income groups should be strengthen and the government should strengthen the construction of market regulations and related mechanism.

\section{Acknowledgements}

This study was supported by a grant from the 70873030 and G200814;

Brief introduction of author: Dezhang Wang(1951-), male, Professor and Doctoral supervisor in Harbin University of Commerce; The main research direction: Theory of market and policy of industrial development, Marketing management of agricultural product; Tel: 13803645704, E-mail: mrwdz@sina.com

\section{References}

[1] H. I. Hsiao , R. G. M. Kemp etal. A classification of logistic outsourcing levels and their impact on service performance: evidence from the food processing industry.

International journal of production economics , 2010(124):75-86

[2] Omar Ahumada, J. R ene Villalobos. Operational model for planning the harvest and distribution of perishable agricultural products. International journal of production economics , 2011(133):677-687 